\title{
Toward an Interdisciplinary Science Curriculum: Analysis of the Connections across Science Learning Progressions
}

\author{
Hye Sun You, Cesar Delgado \\ The University of Texas at Austin, USA
}

\begin{abstract}
Learning progression (LP) studies potentially bring vertical coherence to individual big ideas in science education. However, since natural phenomena are associated with big ideas in a variety of science disciplines, the interdisciplinary connections across big ideas should be considered in science education. This study addresses an important question to developing an exemplary interdisciplinary curriculum: how do existing LPS relate to one another across disciplinary boundaries? This research analyzed 17 published LPs for 10 big ideas: matter, genetics, energy, carbon cycling, force and motion, celestial motion, biodiversity, evolution, ecological systems, and water. A content analysis was conducted to establish how these big ideas formed interdisciplinary relationships. A three-dimensional representation of the LPs including their levels and the interconnections among levels was developed. The approach modeled in this study can inform the development of standards and materials for an interdisciplinary science curriculum.
\end{abstract}

\section{Introduction}

Current science education is discipline-based, with subjects such as biology, chemistry, physics, and earth sciences. Within each discipline, our curricula are "a mile wide and an inch deep" [40]. A lack of coherence and the superficial coverage of a broad range of concepts in a curriculum inhibit integrated understanding within a discipline [41]. Learning progressions (LPs) can potentially address the fragmented nature of the US curriculum, serving as a useful tool in the design of vertically cohesive disciplinary curricula [15]; [45]. However, a second curricular problem exists, one that LP research has not addressed: the lack of horizontal coherence across disciplines. It is important to recognize that disciplinary distinctions are artificial. Any particular kind of natural phenomena is associated with the core ideas of a variety of disciplines. Each core idea cannot belong to a single discipline in the $\mathrm{K}-12$ science education curriculum, for each big idea might be a prerequisite for a big idea in another area of science. The field of science education research will need to think about how individual LPs focusing on individual core ideas can be woven into a cohesive curriculum for all of science. An interdisciplinary approach will allow students to recognize how big ideas in the scientific fields are articulated to one another, which will help them to activate horizontal transfer (Schunk [42]; Tyler, [51]), and in turn enhance meaningful learning.

Many educational scholars have asserted that an interdisciplinary approach may make "learning easier... more realistic and potentially more useful to the student" [43]. Standards documents at the national level also indicate an interest in and need for interdisciplinary approach within science fields (American Association for the Advancement of Science, [AAAS] [53]); National Research Council [NRC] [29]; Next Generation Science Standards ([NGSS] Lead States [33]). This study contributes to the development of an exemplary interdisciplinary science curriculum by exploring how individual LPs focusing on individual big ideas can be woven into a cohesive curriculum. The interdisciplinary model of LPs might be a potential way of providing both vertical and horizontal coherence and further, of promoting interdisciplinary learning. In the light of the need for interdisciplinary science learning, our study focuses on the following research question: how do existing LPs relate to one another across disciplinary boundaries?

\section{Theoretical framework}

\subsection{Learning progressions}

The idea of learning progressions first emerged from two papers commissioned by the National Research Council's Committee on Test Design for K-12 Science Achievement. One paper dealt with matter [47], and another with evolution [6]. Since then, many in the LP community have adopted Wilson and colleagues' work with "construct maps", which track student learning along "progress variables" [52]. The work of Masters and Forster with "progress maps" also influenced the seminal LP work [27]. Perhaps the most widely accepted definition of LPs is that they are "descriptions of the successively more sophisticated ways of thinking about a topic that can follow one another as children learn about and investigate a topic over a broad span of time (e.g., 6 to 8 years) (NRC [29])." However, definitions vary across LP research groups, 
depending on the range of scope, grain size, and target audience [3].

The LP approach is based on cognitive psychology concepts such as 'transfer of learning', 'conceptual change', and 'expert-novice theory'. LPs incorporate constructivists' view in regards to science education [39].

LPs have the following characteristics: LPs a) are based on empirical and conceptual analysis [47]; b) are bounded by upper anchor and lower anchor, and include levels that are "reasonably coherent networks of ideas and practices and that contribute to building a more mature understanding" presenting intermediate understanding (NRC [29]); c) are framed by big ideas, i.e., conceptual knowledge in a content domain [3]; NRC [29]) d) are developed through an iterative process. Duncan and HmeloSilver proposed that LPs have hypothetical paths that differ according to contexts such as students' prior knowledge, experience, materials, and instruction [11]. The hypothetical LPs should go through multiple rounds of empirical testing and revising based on assessment data; this process reinforces the evidence for the validity of HLPs.

LPs have been discussed as a promising framework for building a vertically coherent curriculum in science content [2]. LPs create "a strategic sequencing that promotes both branching out and forming connections between ideas related to a core scientific concept" [49]. Besides informing curriculum development, LPs provide a profound insight into instruction and assessment by tracking paths in students' understanding and progressions pertaining to big ideas.

\subsection{Interdisciplinary learning in science}

There is a growing awareness of the inherent values and benefits of interdisciplinary learning within science. The term "interdisciplinary" was coined in the early decades of the twentieth century and the term has been used for over 100 years [23]. Scholars have started to pay close attention in designing and managing interdisciplinary curricular and research projects, the practical and philosophical consequences of relationships between particular disciplines, and the nature of interdisciplinary theories and methods [23]. The number of published journals and books dealing with the importance of interdisciplinary learning and teaching has greatly increased in recent decades (Gehrke, 1998). A variety of education reform documents (AAAS, 1993; NGSS Lead States [33]; NRC [30]; NSTA, 1998) reflected the considerable amount of interest in interdisciplinary learning for students.

Several contemporary scholars have highlighted the benefits of interdisciplinary learning [4]. Lattuca et al. argued that interdisciplinary learning is effective by, a) “engaging students' prior knowledge and experience," b) "encouraging effective thinking," c) "developing multiple perspectives," d) " motivating students to learn," and e) "constructing meaning in the classroom" [25]. Jacob (1989) also stated that interdisciplinary learning could develop students' higher-order way of thinking and critical thinking, core components of learning.

\subsection{Expert-novice theory}

A broad body of research has explored differences in the ways experts and novices approach problems and organize their knowledge. Expert-novice research provides a promising theoretical perspective on interdisciplinary learning. Experts perceive features and meaningful patterns of information which are not available to novices [5]. Further, experts' knowledge structure on a particular topic is large and well-connected, so they acquire new information more readily and their prior knowledge is more accessible for use [19]. Kozma and Russell provided key principles of experts' knowledge [24]. "The knowledge of experts consists of a large number of interconnected elements that are stored and recalled as extended, coherent chunks of information organized around underlying principles in specific domains" (p.2). The same principles could be applied to further structure knowledge across disciplines. Beginners tend to know discrete facts; they focus on surface features of a topic and often fail to connect relationships among different domains.

When solving problems, experts tend to search for core concepts and central theoretical constructs of the corresponding field first, and then utilize them in order to solve problems that are related with the given concept. Novices, on the other hand, tend to possess shallow concepts and isolate them as separate factual knowledge; they focus on surface features of problems rather than their underlying concepts or principles, and often jump to the rote application of procedures [5]. The differences in cognitive processes between experts and novices provide a basis for understanding the nature of interdisciplinary learning. Experts have a wider range of existing knowledge than novices, but the knowledge of experts is also better connected [7]. For example, Simon and Chase's study showed that expert chess players could not only identify isolated patterns, but also perceive an integrated configuration of chess piece positions [46]. In contrast, novice players did not construct interconnected links. In the learning process as well, the knowledge of novices is limited and insufficient in understanding the given core concepts and tends to have a lower sensitivity in recognizing the relationships between patterns and hierarchical classification of knowledge [5]. 
Chi and Ceci's (adapted from Keil, 1981) representations of the gradually changing structural organization of knowledge provide a way of thinking about how interdisciplinary understanding may be constructed [7]. Figure 1 shows the development of "super links" that connect previously isolated bodies of knowledge. This process cannot only describe the development of general learning in a domain, but also the process of development of interdisciplinary learning. Novice students tend to acquire the knowledge in an isolated manner, which in turn may fail to present how that knowledge overlaps with different disciplines. As shown in figure 1, as learning processes proceeds with time, cognitive structures are changed qualitatively and quantitatively in ways in which the disconnected knowledge components have a "local coherence", which in turn provides "super links" between each module of knowledge. These coherently developed structures of knowledge with super links allow expert students to see or understand the entire knowledge structure as well as interdisciplinary understandings.

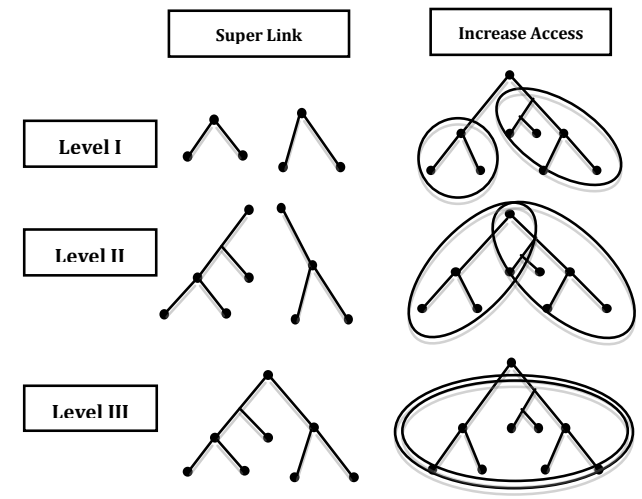

Figure 1. Developmental sequences representing structural changes. Adapted from "Content

knowledge: Its role, representation and restructuring in memory development," by M. T. Chi, and S. J. Ceci, 1987, Advances in Child Development and Behavior, 20, p. 131. Copyright 1987 by the New York Academic Press

The second example of developmental structure changes illustrates Rozin's theory of access [38]. Even though learners have an entire and relevant amount of knowledge in long-term memory, there might be differences in the ability to access a wider range of the knowledge structure between novices and experts. The "Increase access" column of figure 1 shows the links among the different concepts and the interconnected areas where access is possible. Level 1 thinkers can only access some overlapping knowledge, while Level III thinkers can access the entire knowledge base to solve a specific task. It is assumed that the accessibility of the knowledge when it is interconnected might serve to facilitate interdisciplinary understanding.

\subsection{Piagetian constructivism}

Piagetian constructivism provides a supportive argument and theoretical foundation for interdisciplinary learning in that it explains principles of knowledge construction and internalization [16]. Piaget [35] used the concepts of schemas (i.e., concepts or representations of an aspect of the world), assimilation (the placing of new information into existing schemas), and accommodation (transforming existing schemas or creating new ones) to explain cognitive development and learning processes. The organization of schemas is achieved through the consideration and acknowledgement of the connections inherent in the external stimuli, and if children start recognizing these connections they assimilate new information into their already existing structures.

Piaget found that young children naturally tend to fail "big picture" thinking since they tend to know isolated concepts and unrelated information [34]. Interdisciplinary learning helps learners develop and organize complex knowledge, and creates connections through accommodation between newly assimilated integrated concepts. This interdisciplinary learning also stimulates the learners' understanding of higher-order relationships among knowledge structures [17]. Piagetian theorists generally believe that children individually develop their own brand of cognitive structures internally through encountering disequilibrium with the environment [10]. Interdisciplinary education could provide students with an environment creating certain types of disequilibrium where they accommodate prior disconnected knowledge and restructure their mental models in order to activate knowledge already acquired and to create meaningful connections among prior cognitive structures.

\section{Methods}

We conducted a qualitative content analysis in an inductive way, grounding the examination of the connections among big ideas, as well as some inferences drawn from them. In order to select the appropriate LP literature targeting K-12 science education, purposive sampling [9], one of the most commonly used methods in content analysis studies, was used. In purposive sampling, decisions need to be made about what LP studies are sampled. The papers were selected from a special issue on LPs in the Journal of Research in Science Teaching, the journal Science Education, the Learning Progressions in Science (LeAPS) conference, and the Consortium for Policy Research in Education. Additionally, we searched electronic database including ISI Web of Science, ERIC EBSCO, Academic Search Premier, PsycINFO, and ProQuest 
dissertations and theses. Additionally, web searches of Google and Google Scholar were conducted. In terms of criteria for selecting appropriate LP literature, this study focused on LPs that were constructed through systematic empirical research. Papers that dealt with theoretical, policy, or assessment issues of LPs were not included. Neither did we include LPs for scientific practices that did not also explicitly include a progression for a core disciplinary science idea. The thorough selection process resulted in the collection of published studies including 10 big ideas which were matter, energy, carbon cycling, force and motion, celestial motion, biodiversity, evolution, ecology, genetics, and water. For matter, four LP papers were selected and examined for characteristics of core ideas with some levels suggested in each LP [1]; CPRE, 2011; Smith, Wiser, Krajcik and Anderson [47]; Stevens et al [49]. In genetics and celestial motion, LP models from two different studies were used (genetics: Duncan, Rogat, and Yarden [13], and Duncan and Tseng [12]; celestial motion: Plummer and Krajcik [36]; Plummer and Maynard [37]). Three energy LP studies were included [22]; Lee and Liu [26], Neumann et al. [32]). Because LP literature focusing on big ideas other than matter, genetics, celestial motion, and energy is rare, only one study was included for each of the remaining topics: carbon cycling [28], force and motion [2], biodiversity [48], evolution [6], ecological systems [20], and water [18]. This study analyzed their content to see how these big ideas formed interdisciplinary relationships in a horizontal manner. A representation of the interdisciplinary relationships across 10 big ideas was generated in order to visually depict the connections encountered.

\section{Results}

\subsection{Principal findings}

We next describe our principal findings for the analysis of the LPs for each of the 10 big ideas, followed by our analysis of their interconnections.

Matter: The Consortium for Policy Research in Education (CPRE) at Teachers College [8] developed a set of exemplary hypothetical learning progressions based on matter and atomic-molecular theory. CPRE (2011) and Smith and colleagues [47] suggested LP models for matter and atomicmolecular theory, including properties of matter (e.g., density, properties of different states of matter, etc.), transformations (e.g., reshaping, cutting, changes of phase), and conservation during physical transformations (e.g., grinding, melting, freezing). CPRE level 3 students understand the particle model of matter. In grades 6-8 (Smith et al. [47]) and grades 7-9 (CPRE level 4), the concept of atoms and chemical change are present. Grades 10-12 (CPRE level 5) introduced subatomic particles (e.g., electrons, protons and neutrons), electrostatic forces, the movement of the electrons, and concepts of energy and stability during chemical reactions.

Stevens et al. [49] developed a hypothetical learning progression (HLP) from empirical data that characterizes how grade 7-12 students develop their knowledge regarding atomic structure and electrical forces that govern interactions at the nano-, molecular, and atomic scales. This multi-dimensional HLP extends the LP for the atomic molecular theory for K-8 students previously proposed by Smith et al. [47], defining the sets of ideas that lead to more sophisticated understanding of the structure and behavior of matter. Adadan, Trundle, and Irving investigated the conceptual pathways of grade 11 students for the particulate nature of matter (PNM) [1]. Students' conceptual pathways focus on the interaction between their existing conceptions and multirepresentational instruction, which might give rise to observing multiple paths in promoting students' conceptual understanding and maintaining newly constructed scientific understandings of the PNM.

Genetics: Duncan, Rogat, and Yarden [13] described the learning of core concepts in modern genetics over grades 5-10. The concept of genes and essential functions of cells were presented in grades 5-6. In grades 7-8, central role of proteins and cell division were discussed, and in grades 9-10, DNA, nucleotide, chromosomes, and amino acids as components of proteins were involved. Duncan and Tseng [12] suggested design-based research for fostering a genetics curriculum, including protein functions determined by amino acids sequence, how genes code for proteins, and genetic phenomena.

Carbon cycling: Mohan, Chen, and Anderson developed a LP focusing on carbon-transforming processes [28]. They specifically compared and contrasted elementary, middle, and high school students' accounts in terms of four key elements: life, materials, scale, and models. Level 1 is in the stage of visible macroscopic observation, and differentiating dead things from living organisms. Level 2 shows the description of "hidden mechanisms" in students' accounts. Students of level 2 can recognize gases as matter; learn about the structure of organs and cells, and about the movement of materials and energy. Level 3 is usually observed in high school students, and includes the description of chemical change. The upper anchor (level 4) contained the concept of matter-energy conservation, the mass conservation principle during chemical changes and substances such as lipids, carbohydrates, and proteins. Even though several materials were described at the atomic-molecular level, students held a limited knowledge of the atomic structure of materials. 
Energy: Lee and Liu presented a construct-based assessment approach to measure a LP of the concept of energy across physical, life, and earth science contexts in a middle school curriculum [26]. Their LP model demonstrates the level of knowledge integration of middle school students concerning energy sources, energy transformation, and energy conservation across grade levels. Energy conservation and transformation require higher knowledge integration levels than singular ideas such as energy sources. Jin and Anderson [22] developed a LP focusing on students' accounts of using energy concept in the carbon-transforming processes. Level 1 accounts are force-dynamic about cause-effect relations with relying on everyday language. Level 2 students are still force-dynamic in character, though they recognized energy as a physical necessity. Level 3 accounts include ideas about atoms, molecules, forms of energy, and conservation laws. Only level 4 students could correctly relate energy transformation to matter transformation. Neumann et al. proposed an initial learning progression of energy based on an empirical study employing assessment items [32]. To create the levels, they analyzed item difficulty and assigned them to "conceptions". The lowest average item difficulty is for the conception "forms and sources", whereas items regarding "energy conservation" have the highest average item difficulty. Item difficulty related to "transfer and transformation" and "degradation" is in the middle range.

Force and motion: Alonzo and Steedle [2] developed students' learning progression levels on a force and motion LP using two assessments with different types of items: ordered multiple-choice and open-ended. A LP of force and motion targeting middle school students is illustrated as 5 levels. In level 1, students understand force as a push or pull, and level 2 shows the relationship between motion and force. Level 3 includes the relationship between net force and motion along with the (mistaken) belief that there is a proportional relationship between objects' speed (not acceleration) and net force. Level 4 students begin to understand the more accurate concept that net force induces acceleration proportionally.

Celestial motion: Plummer and Krajcik [36] describe the process of developing a learning progression for apparent (i.e., Earth-based) celestial motion (path of the sun, orbit of the moon, patterns of stars, phases of the moon) through the construction of learning trajectories (smaller-grained components of LPs). They focused on elementary students' development of astronomy concepts in a planetarium. Four inter-related explanatory models form the basis of four separate learning trajectories, in which the levels range from least (level 1) to most sophisticated (level 3 or 4) description of a characteristic. Plummer and Maynard developed and revised the seasons construct map for the seasons, as a subset of a larger LP on celestial motion using the construct modeling approach [37]. Unlike LPs, construct maps focus on a smaller grain-size than a big idea in the analysis of learning science.

Biodiversity: Songer, Kelcey and Gotwals [48] followed an empirically driven, five-step process to develop a LP for fourth-sixth graders, focusing on biodiversity (they also focused on scientific practices, not covered here). The learning progression contains 12 focal points in the sub areas of classification, biodiversity, and ecology. This paper begins with fourth grade, and then adds four classification ideas in fifth grade. Ecology is introduced in fourth grade (e.g., food chain, energy of organisms), and these concepts are deepened in sixth grade (e.g., the impacts on a food web from changes in the number of one species, factors affecting biodiversity of ecosystems).

Evolution: Catley, Lehrer, and Reiser proposed a prospective learning progression for evolution across K-8 grade bands [6]. K-2 students focus on the basic definition of organisms, their attributes and habitat, and changes over their lifespan. Grade 3-5 students deal with the classification of species by their characteristics, associations of species type and habitat quality, the themes of organismic variation, and the emphasis on the functional change of individual organisms. Grade 6-8 students are expected to understand intraspecies variation, the reason for diversity, the notion of interrelationship, and factors affecting organisms' survival (e.g., stress, changes of environment etc.).

Water: Gunckel et al. developed a LP to investigate understanding of students in grades 5-12 about water and substances in water [18]. Level 1 accounts focus on human uses of water and are limited to a macroscopic description of water. Level 2 accounts show force-dynamic reasoning with mechanism to move water or change water. Level 3 students reveal a microscopic view of water and identify different types of substances in water. Level 4 accounts identify the chemical nature of water such as ionic and hydrogen bonds at the atomic-molecular scale.

Ecological systems: Hokayem developed a HLP of lower elementary students' systemic reasoning about species interactions in an ecosystem [20]. Level 1 represents anthropomorphic reasoning where students only refer to organisms based on human characteristics without any external mechanism or cause. Level 2 students begin to use external mechanisms that influence change in ecosystem. Level 3 students recognize the complex interaction in the ecosystem by thinking of various effects or causes. Level 4 students show more complicated network of relations in the ecosystem. At this level, students consider the interdependency of organisms and identify how most parts of the system may be 
affected when a specific change happens in one of its elements.

\subsection{Analysis}

Figure 2 shows the complicated connections across the LPs for the 10 big ideas. Both M1 (matter level 1) and CC1 (carbon cycling level 1) have a common component with visual macroscopic change and physical change of materials. M2 shares the conservation principle and the microscopic model in which materials consists of smaller sized parts, with CC2. Beyond that, the concept about atom (M4) and sub-atomic models (M5) will support future learning as concerns the structures and behaviors of other molecules such as glucose, DNA, amino acids and proteins (CC4). Mastery of chemical change of matter (M4) is a prerequisite for proceeding toward CC3 and CC4. FM4 (force and motion level 4) is a prerequisite to understanding electrostatic force and Coulombs' Law in M5. Grasping the energy transformation/conservation principle (ET) early on allows students to engage with opportunities for sophisticated learning about phase changes (M4) and properties of gas, depending on temperature or pressure, for sophisticated learning (M4). M1 also has a relationship with Ev K-2 (evolution K-2 grade level) in terms of focusing on external features of objects or organisms. Energy-matter conversion in $\mathrm{CC} 4$ relies on the concept of energy transformation (ET). To distinguish matter from energy (CC4) in carbon cycling, the atomic-molecular concept (M4) is required. $\mathrm{CC} 3$ and $\mathrm{G} 1$ have concepts regarding the function and structure of cells in common. Also, the biological molecules (e.g., lipids, carbohydrates, and proteins) represented in $\mathrm{CC} 4$ are necessary parts in genetics level 2 (G2). M4 also has a significant effect on understanding structures and other characteristics of the molecules involved in G3 (e.g., amino acids, proteins, DNA) and CC4.

As can be easily seen in Figure 2, diversity, evolution, ecology and genetics are closely intertwined with one another as core ideas of biology. It can be said that evolution accounts for the core ideas of biodiversity, genetics, and ecology in an integrated manner. Evolution contains the concept of diversity that organisms have distinct characteristics and the relationships between habitat (biodiversity) and the species types (ecology). Evolution and genetics share the concept of change; the environment can affect cell function through changes at the protein level. Even environmental factors could cause mutation in genes, which may brings changes in their traits and behavior, influencing survival of individuals or populations.

Celestial motion at the elementary level and force and motion are relatively independent core ideas, unrelated to the LPs for other big ideas except for each other and matter. It is expected that if celestial motion LPs beyond the elementary grades were developed, a stronger interrelationship with other core ideas would be present. Water only shows an interrelationship with matter. The chemical nature of water is based on an atomic-molecular model of matter in which particles are considered to be composed of one or more atoms that make up a molecule.

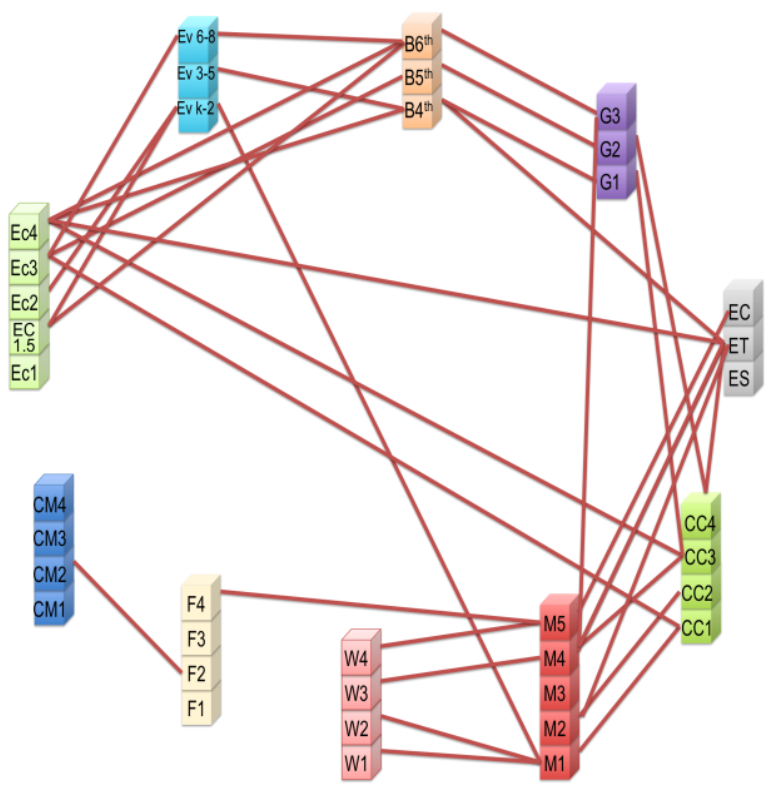

Figure 2. A three-dimensional representation that shows the relationship with big ideas of science in learning progression (M: matter, CC: cycling, $\mathrm{E}$ : energy, (S: source, $\mathrm{T}$ : transformation, $\mathrm{C}$ : conservation) G: genetics, B: biodiversity, Ev: evolution, Ec: ecological system, CM: celestial motion, F: force and motion, W: water). The numbers represents the levels and grade (4th, 5th, 6th), and grade bands (K-2, 3-5, 6-8)

As shown in figure 2, matter overall is closely related to the biology LPs, energy, carbon cycling, and water, which implies the importance of matter as a scientific core idea.

The connections represented in figure 2 can be leveraged by curriculum and standards developers in creating a horizontally and vertically integrated curriculum. Much additional work will be required connected to the appropriate grade level sequencing. While some LPs list concepts by grades or ranges of grades, others only suggest levels that are not tied to specific grades. Furthermore, it remains to be investigated whether LP-guided curriculum and instruction can lead to students' learning concepts at earlier ages. While this work is a considerable challenge, the creation of a vertically and horizontally integrated curriculum should take into account the best existing research on student learning, which has been compiled into LPs. 


\section{Discussion and implications}

Science education has traditionally arranged the curriculum into units that reflect academic disciplines, each of which have developed their specialized ways of knowing to explore the natural phenomena. The science LP research base contributes to providing a road map showing how students' understanding of particular big ideas is likely to change over time. As such, LPs could help teachers and other educators in making decisions for instruction, for the development of assessments that properly monitor students' progress, as well as to achieve greater vertical coherence in their curriculum. However, focusing only on individual big ideas as represented in LPs could inhibit students' interdisciplinary learning, creating artificial boundaries among big ideas. This study describes work toward developing an interdisciplinary model using the existing LP studies. The emphasis on making the connections both within and among big ideas in the LPs informs efforts to construct curriculum, instruction, and assessment that foster interdisciplinary understanding. To achieve robust interdisciplinary understanding, students should be equipped with scientific knowledge beyond a single discipline and be able to draw from and connect the knowledge from multiple science disciplines. It is our hope that the interdisciplinary model of LPs developed in this study offers a large-scale map for a coherently organized science curriculum that will help students build interdisciplinary understanding.

\section{References}

[1] Adadan, E., Trundle, K. C., \& Iriving, K. E. (2010). Exploring grade 11 students' conceptual pathways of the particulate nature of matter in the context of multi representational instruction. Journal of Research in Science Teaching, 47(8), 1004-1035.

[2] Alonzo, A. C., \& Steedle, J. T. (2009). Developing and assessing a force and motion learning progression. Science Education, 93(3), 389-421.

[3] Battista, M. T. (2011). Conceptualizations and issues related to learning progressions, learning trajectories, and levels of sophistication. The Mathematics Enthusiast, 8(3), 507-570.

[4] Boix Mansilla, V., \& Duraisingh, E. D. (2007). Targeted assessment of students' interdisciplinary work: An empirically grounded framework proposed. The Journal of Higher Education, 78(2), 215-237. doi:10.1353/jhe.2007.0008

[5] Bransford, J. D., Brown, A. L., \& Cocking, R. R. (2000). How People Learn: Brain, Mind, Experience, and School: Expanded Edition. Washington, D. C.: National Academy Press.
[6] Catley, K. M., Lehrer, R., \& Reiser, B. J. (2005). Tracing a prospective learning progression for developing understanding of evolution. Paper Commissioned by the National Academies Committee on Test Design for K-12 Science Achievement.

[7] Chi, M. T. H., \& Ceci, S. J. (1987). Content knowledge: Its role, representation and restructuring in memory development. In H. W. Reese (Ed.), Advances in Child Development and Behavior (Vol. 20, pp. 91-142). New York: Academic Press.

[8] Consortium for Policy Research in Education (2011). Developing learning progressions in support of the new science standards: A rapid workshop series.

[9] Creswell, J. W. (2013). Qualitative inquiry and research design: Choosing among five approaches. Thousand Oaks, CA: Sage.

[10] Driscoll, M. (1994). Psychology of learning for instruction. Boston: Allyn and Bacon.

[11] Duncan, R. G., \& Hmelo-Silver, C. E. (2009). Learning progressions: Aligning curriculum, instruction, and assessment. Journal of Research in Science Teaching, 46(6), 606-609.

[12] Duncan, R. G., \& Tseng, K. A. (2011). Designing project-based instruction to foster generative and mechanistic understandings in genetics. Science Education, 95(1), 21-56.

[13] Duncan, R. G., Rogat, A. D., \& Yarden, A. (2009). A learning progression for deepening students' understandings of modern genetics across the 5th-10th grades. Journal of Research in Science Teaching, 46(6), 655-674.

[14] Duncan, R.G., \& Hmelo-Silver, C.E. (2009). Learning progressions: Aligning curriculum, instruction, and assessment. Journal of Research in Science Teaching,46(6), 606-609.

[15] Duschl, R. A., Maeng, S., \& Sezen, A. (2011). Learning progressions and teaching sequences: A review and analysis. Studies in Science Education, 47(2), 123182.

[16] Foss, D. H., \& Pinchback, C. L. (1998). An interdisciplinary approach to science, mathematics, and reading: Learning as children learn. School Science and Mathematics, 98(3), 149-55. doi:10.1111/j.1949 8594.1998.tb17408.x

[17] Goldsmith, T., \& Kraiger, K. (1996). Applications of structural knowledge assessment to training evaluation. In J. K. Ford, S. Kozlowski, K. Kraiger, E. Salas, \& M. Teachout (Eds.), Improving training effectiveness in work organizations (pp. 73-97). Mahwah, NJ: Lawrence Erlbaum.

[18] Gunckel, K. L., Covitt, B. A., Salinas, I., \& Anderson, C. W. (2012). A learning progression for water in 
socio-ecological systems. Journal of Research in Science Teaching, 49(7), 843-868. doi:10.1002/tea.21024

[19] Hall, R., \& Greeno, J. G. (2008). Conceptual learning. In T. Good (Ed.), 21st Century education: A reference handbook (pp. 212-221). London: Sage.

[20] Hokayem, H. A. (2012). Learning progression of ecological system reasoning for lower elementary (G1-4) students. ProQuest, UMI Dissertations Publishing).

[21] Jacobs, H. H. (Ed.). (1989). Interdisciplinary curriculum: Design and implementation. Alexandria, VA: Association for Supervision and Curriculum Development.

[22] Jin, H., \& Anderson, C. W. (2012). A learning progression for energy in socio-ecological systems. Journal of Research in Science Teaching, 49(9), 11491180. doi:10.1002/tea.21051

[23] Klein, J. T. (1990). Interdisciplinarity: History, theory, and practice. Detroit: Wayne State University.

[24] Kozma, R. B., \& Russell, J. (1997). Multimedia and understanding: Expert and novice responses to different representations of chemical phenomena. Journal of Research in Science Teaching, 34(9), 949-968.

[25] Lattuca, L., Voigt, L., and Fath, K. (2004). Does interdisciplinarity promote learning? Theoretical support and researchable questions. Review of Higher Education, 28(1), 23-48.

[26] Lee, H., \& Liu, O. L. (2010). Assessing learning progression of energy concepts across middle school grades: The knowledge integration perspective. Science Education, 94(4), 665-688.

[27] Masters, G., \& Forster, M. (1997) Developmental Assessment, ACER Assessment Resource Kit. Camberwell, AU: Australian Council for Educational Research.

[28] Mohan, L., Chen, J., \& Anderson, C. W. (2009). Developing a multi-year learning progression for carbon cycling in socio-ecological systems. Journal of Research in Science Teaching, 46(6), 675-698.

[29] National Research Council. (2007). Taking Science to School:Learning and Teaching Science in Grades $K$ 8. Committee on Science Learning, Kindergarten Through Eighth Grade. Richard A. Duschl, Heidi A. Schweingruber, and Andrew W. Shouse, Editors. Board on Science Education, Center for Education. Division of Behavioral and Social Sciences and Education. Washington, DC: The National Academies Press.

[30] National Research Council. (2012). A framework for K-12 science education: Practices, crosscutting concepts, and core ideas. Washington, DC: National Academies Press.

[31] National Science Teachers Association. (1998). The national science education standards: A vision for the improvement of science teaching and learning. Science Scope 21(8), 32-34.

[32] Neumann, K., Viering, T., Boone, W. J., \& Fischer, H. E. (2013). Towards a learning progression of energy. Journal of Research in Science Teaching, 50(2), 162-188. doi:10.1002/tea.21061

[33] NGSS Lead States. (2013). Next Generation Science Standards: For States, By States. Washington, DC: The National Academies Press.

[34] Piaget, J. (1975). A Child's Conception of the World. Toitowa, NJ: Rowman \& Littlefield.

[35] Piaget, J. (1978). The development of thought (A. Rosin, Trans.). Oxford: Basil Blackwell.

[36] Plummer, J. D., \& Krajcik, J. S. (2010). Building a learning progression for celestial motion: Elementary levels from an earth-based perspective. Journal of Research in Science Teaching, 47(7), 768-787.

[37] Plummer, J. D., \& Maynard, L. (2014). Building a learning progression for celestial motion: An exploration of students' reasoning about the seasons, Journal of Research in Science Teaching. Advance online publication. doi:10.1002/tea.21151.

[38] Rozin, P. (1976). The evolution of intelligence and access to the cognitive unconscious. In J.M. Sprague \& A. A. Epstein (Eds.), Progressive in psychobiology and physiological psychology (Vol. 6, pp. 245-280). New York: Academic Press.

[39] Salinas, I. (2009). Learning Progression in Science Education: two approaches for development. Unpublished conference paper, the Learning Progressions in Science (LeaPS) Conference, Iowa City, IA.

[40] Schmidt, W. H., McKnight, C. C., \& Raizen, S. A. (1997). A splintered vision: An investigation of U.S. science and mathematics education. Hingham, MA: Kluwer.

[41] Schmidt, W.H., Wang, H.C., \& McKnight, C.C. (2005). Curriculum coherence: An examination of US mathematics and science content standards from an international perspective. Journal of Curriculum Studies, 37(5), 525-559.

[42] Schunk, D. (2004). Learning theories: An educational perspective (4th ed.). Upper Saddle River, NJ, USA: Pearson.

[43] Shell, D. F., Brooks, D. W., Trainin, G., Wilson, K. M., Kauffman, D. F., \& Herr, L. M. (2010). The unified learning model: How motivational, cognitive, and neurobiological sciences inform best teaching practices. London: Springer.

[44] Shin, N., Stevens, S. Y., \& Krajcik, J. (2010). Using student learning over time. In (Ed). S. Rodrigues, Using analytical frameworks for classroom research: collecting data and analyzing narrative (pp. 38-58), Routledge, Taylor \& Francis, London. 
[45] Shin, N., Stevens, S.Y., Short, H., \& Krajcik, J. (2009, June). Learning progressions to support coherence curricula in instructional material, instruction, and assessment design. Paper presented at the Learning Progressions in Science (LeaPS) Conference, Iowa City, IA.

[46] Simon, H. A., \& Chase, W. G. (1973). Skill in chess. American Scientist, 61(4), 394-403.

[47] Smith, C. L., Wiser, M., Anderson, C. W., \& Krajcik, J. S. (2006). Implications of research on children's learning for standards and assessment: A proposed learning progression for matter and the atomic molecular theory. Focus Article. Measurement: Interdisciplinary Research and Perspectives, 14, 1-98.

[48] Songer, N. B., Kelcey, B., \& Gotwals, A. W. (2009). How and when does complex reasoning occur? Empirically driven development of a learning progression focused on complex reasoning about biodiversity. Journal of Research in Science Teaching, 46(6), 610-631.

[49] Stevens, S. Y., Delgado, C., \& Krajcik, J. S. (2010). Developing a hypothetical multi-dimensional learning progression for the nature of matter. Journal of Research in Science Teaching, 47(6), 687-715. doi:10.1002/tea.20324

[50] Stevens, S. Y., Shin, N., Delgado, C., Krajcik, J., Pellegrino, J. (2007). Developing a Learning Progression for the Nature of Matter as it Relates to Nanoscience. Retrieved on September 30, 2008 from hice.org/presentations/documents/ UM_LP_AERA_2007.pdf

[51] Tyler, R. W. (1969). Basic principles of curriculum and instruction. Chicago: University of Chicago Press.

[52] Wilson, M. (2009). Measuring progressions: Assessment structures underlying a learning progression. Journal of Research in Science Teaching, 46(6), 716-730. doi:10.1002/tea.20318.

[53] American Association for the Advancement of Science. (1993). Benchmarks for science literacy. New York: Oxford University Press. 